\title{
Correspondence
}

\section{Congenital dislocation of the hip and short maternal stature}

Sir,

We were interested to read the paper by Amitai et al. ${ }^{1}$ reporting an association between congenital dislocation of the hip $(\mathrm{CDH})$ and short maternal stature, based on a study of 33 consecutive cases and 54 controls $(P<0.01)$. We have been interested in the aetiology of $\mathrm{CDH}$ for many years and have just completed a study of 455 infants with $\mathrm{CDH}$ born in the care of the university service in Bristol, so it was easy to scan our records to find out if our data supported this new observation.

Among the 455 infants with CDH born between 1970 and 1979 all but 10 cases were diagnosed in the neonatal period. Maternal height was available in 330 cases. We took as our controls randomly selected mothers of babies born in our hospital during the same period who did not have $\mathrm{CDH}$. The maternal height of the two groups was then compared, first in 5-cm subgroups and then as in the Figure below; there was clearly no statistical difference between the two groups. We conclude that whatever may be the case in Israel, in Britain short maternal stature does not appear to be associated with CDH.

We thank the Van Neste Foundation for support.

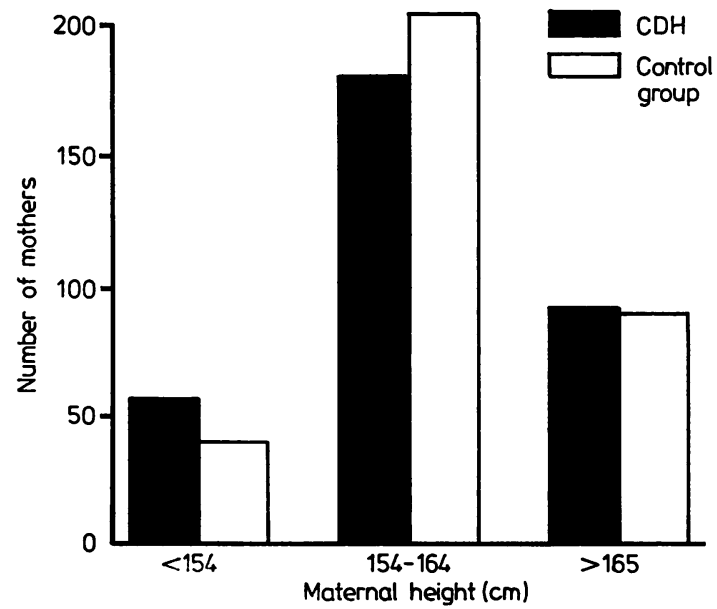

Figure Distribution of maternal height in association with 330 infants with congenital dislocation of the hip and controls, born in Bristol, 1970-79.

\section{Reference}

1 Amitai I, Yarom A, Bloch R, Pogrund H. Congenital dislocation of the hip and short maternal stature. Arch Dis Child 1982; 57: 875-6.

Peter M Dunn, R E Evans, and M Corfield University of Bristol, Department of Child Health, Southmead Hospital, Southmead Road, Bristol BS10 5NB

\section{Necrotising enterocolitis in the very low birthweight infant}

Sir,

Drayton et al. ${ }^{1}$ were so anxious to criticise our paper ${ }^{2}$ that they did not read it properly. All the 'missing' figures concerning the incidence of necrotising enterocolitis (NEC) in preterm infants with birthweight above $1500 \mathrm{~g}$ were given in the results section. ${ }^{3}$

Regarding the age of onset of NEC and the duration of parenteral feeding recommended by us, in Wilson's series $^{4}$ of 148 cases of NEC, 86 of whom were VLBW infants, the median age at onset was 7 days. Average age at onset in Kliegman's ${ }^{5} 123$ NEC patients (70\% VLBW infants) was 12 days. It is true that the age at onset of NEC has an inverse relationship to the gestational age. This is the reason for our recommendation of at least a 3-weeks period of parenteral nutrition in infants weighing $1000 \mathrm{~g}$ and below at birth. If our colleagues from the Southmead Health District wish to carry on with parenteral nutrition beyond this period, all we do can is congratulate them.

Drayton et al. are concerned about biochemical and technical difficulties. During the last 3 years we have not noted any serious adverse effect which could be attributed to parenteral nutrition (nearly 300 infants), and we feel we have avoided many cases of NEC. We think this achievement is much more important than a possible theoretical gain-such as induction of gut hormone production by enteral feeding.

\section{References}

1 Drayton M R, Palmer S R, Speidel B D. Letter: Parenteral feeding and necrotising enterocolitis in very low birthweight infants. Arch Dis Child 1982; 57: 890.

2 Eyal F, Sagi E, Arad I, Avital A. Necrotising enterocolitis in the very low birthweight infant: expressed breast milk feeding compared with parenteral feeding. Arch Dis Child 1982; 57: 274-6.

${ }^{3}$ Eyal F, Sagi E, Arad I, Avital A. Necrotising enterocolitis in the very low birthweight infant: expressed breast milk feeding compared with parenteral feeding. Arch Dis Child $1982 ; 57: 274-6$. 